\title{
SPECTROSCOPIC ANALYSIS OF SOIL METAL CONTAMINATION AROUND A DERELICT MINE SITE IN THE BLUE MOUNTAINS, AUSTRALIA
}

\author{
A. Shamsoddini, S. Raval*, R. Taplin
}

\begin{abstract}
Australian Centre for Sustainable Mining Practices, School of Mining Engineering, University of New South Wales, Sydney, NSW 2152, Australia - (a.shamsoddini, simit, r.taplin)@unsw.edu.au
\end{abstract}

KEY WORDS: Soil, Modelling, Analysis, Prediction, Spectral

\begin{abstract}
:
Abandoned mine sites pose the potential threat of the heavy metal pollution spread through streams and via runoff leading to contamination of soil and water in their surrounding areas. Regular monitoring of these areas is critical to minimise impacts on water resources, flora and fauna. Conventional ground based monitoring is expensive and sometimes impractical; spectroscopic methods have been emerged as a reliable alternative for this purpose. In this study, the capabilities of the spectroscopy method were examined for modelling soil contamination from around the abandoned silver-zinc mine located at Yerranderie, NSW Australia. The diagnostic characteristics of the original reflectance data were compared with models derived from first and second derivatives of the reflectance data. The results indicate that the models derived from the first derivative of the reflectance data estimate heavy metals significantly more accurately than model derived from the original reflectance. It was also found in this study that there is no need to use second derivative for modelling heavy metal soil contamination. Finally, the results indicate that estimates were of greater accuracy for arsenic and lead compared to other heavy metals, while the estimation for silver was found to be the most erroneous.
\end{abstract}

\section{INTRODUCTION}

It is recognised that heavy metals, especially lead, cadmium, mercury, and arsenic can cause severe damage to human health, e.g. cancer, lung damage, and neurotoxic effects (Järup, 2003). Significant exposure to humans and ecosystems may occur when heavy metals contaminate air, water, and soil. Many different sources may lead to heavy metal contamination of the soil among which derelict mines can be one of the most substantial if not properly remediated. Therefore, it is important to regularly monitor the areas surrounding the derelict mine sites, especially those through which the runoff and streams flow to feed the lakes and reservoirs which in turn could be a source of drinking water.

The traditional method which is used for detecting the distribution of the heavy metals in soil, involves raster sampling and laboratory analysis which is both time consuming and expensive for a large area (Kemper and Sommer, 2002; Ren et al., 2009). Development of spectroscopic instruments provides an alternative to these conventional monitoring methods of the soil heavy metal contamination. However, direct identification of the heavy metals as inorganic contaminants of the soil through spectroscopy is challenging since they usually occur in low concentration $(10000 \mathrm{mg} / \mathrm{kg}$ dry soil) and they lack unique absorption features in the visible and near infrared wavelength region (Schwartz et al., 2011). Although pure metals do not have absorption features in the visible/near infrared (VNIR), and short-wavelength infrared (SWIR), their combinations with organic matter as well as their association with hydroxides and carbonates could assist indirect identification of heavy metals (Malley and Williams, 1997). Success in establishing a robust model between soil contamination and ground based spectral characterisation could form a basis for the development of a site specific spectral library that could then be used to map a larger area through satellite based sensors. After measuring the spectra of the soil samples and prior to the modelling phase, spectral pre-processing techniques are utilised to remove the possible noise from the collected spectra (Nicolai et al., 2007). Among different pre-processing methods, derivative transformations are commonly used to remove the baseline effects and superposed peaks. While some studies have reported the benefits of the estimation derived from applying derivative transformations on the original reflectance (Malley and Williams, 1997; Kemper and Sommer, 2002; Butkutë, 2005), this may vary from one case to another. For example, Wu et al. (2005) found inferior accuracy of the estimation of soil mercury contamination through second derivative transformation compared to the use of the original reflectance. Therefore, further research is required to examine the capability of the transformed reflectance against the original reflectance for quantifying the soil heavy metals.

The Blue Mountains National Park (BMNP) part of the Greater Blue Mountains World Heritage Area (GBMWHA) in the State of New South Wales, Australia, has relatively pristine ecosystems. However, the area has had a history of mining activities that commenced more than a century ago and in some cases continued into the 1990s (REF). Some of these mining activities in the BMNP have left a legacy of heavy metal contamination around abandoned mines due to inadequate remedial measures (REF). Spread of these fugitive metals may impact surrounding watercourses and soil. Considering the ecological sensitivity of the area, relatively few studies have been conducted to date. Harrison et al. (2003) studied the distribution of pollutants from the derelict Yerranderie silverlead-zinc mine site (abandoned since the late 1920s) mine in sediments from the nearby Tonalli River. The study found that

\footnotetext{
* Corresponding author
} 
the metal concentrations in the areas closer to the derelict mine site were up to 400 times higher than the accepted level and decreased sharply with distance from the mine. Wright (2006) investigated the pollution from the Canyon coalmine (closed in 1997) into the Grose River system. He found 80 times higher levels of zinc above background in some parts of the river where runoff occurs from areas surrounding the zinc rich coalmine. These findings have generated serious concerns about the remediation of old mines in the area. In particular, the impacts of heavy metal contamination in soil and vegetation have not been explored adequately for this area. The GBMWHA has rough terrain making areas inaccessible for ground-based measurements. Accordingly, development of remote sensing monitoring techniques for this area should assist management of the area's abandoned mine sites.

This study has focussed on the former Yerranderie silver-leadzinc mine and has examined the performance of ground-based spectroscopic data to identify a suitable dataset for quantifying the heavy metal contents of the soil in the vicinity of the derelict mine site. For this purpose the main contaminants in the soil samples were measured by chemical analysis. They were then compared with spectral measurements made in the laboratory. The original reflectance and its first and second derivatives were modelled to estimate heavy metals.

\section{STUDY AREA AND FIELD SAMPLING}

As discussed above, the study area, as shown in Figure 1, is the silver-lead-zinc mining area of Yerranderie located in the BMNP, New South Wales, Australia. Soon after the discovery of galena $(\mathrm{PbS})$ in the area, mining activities started and consequently a number of small underground mines and four processing sites along with the town of Yerranderie were established (Harrison et al., 2003). Mining activities ceased by 1929 because of the construction of Warragamba Dam, a major water supply catchment for the city of Sydney, and the Great Depression (Archer and Caldwell, 2004). Consequently, the Yerranderie mines and processing sites were abandoned. The region is a part of the Tonalli River catchment which flows into Lake Burragorang. Approximately $80 \%$ of the drinking water of Sydney now is provided from this lake (McCotter, 1996), making the area critical for regular monitoring.

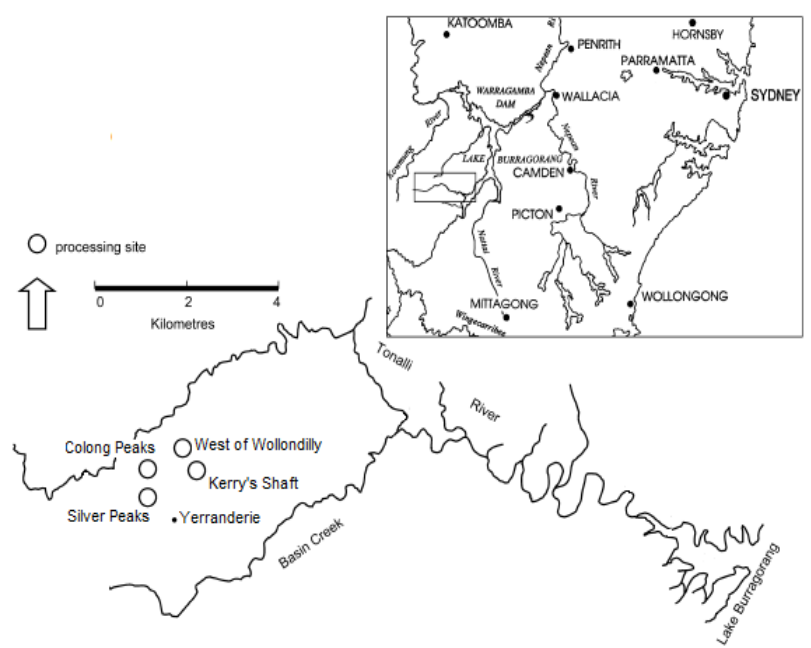

Figure 1. The location of study area (Harrison et al., 2003)
Streams adjacent to two derelict mine shafts, the Silver Peaks shaft (approximately located at $34^{\circ} 07^{\prime} 08^{\prime \prime} \mathrm{S}$ latitude and $150^{\circ}$ $12^{\prime} 28^{\prime /}$ E longitude) and the Colon Peaks shaft (approximately located at $34^{\circ} 06^{\prime} 58^{\prime \prime} \mathrm{S}$ latitude and $150^{\circ} 12^{\prime} 27^{\prime \prime}$ E longitude) were selected for data collection for this study.

There are two main streams that flow downward towards the Tonalli River from these mine shafts. 53 soil samples were collected on $13^{\text {th }}$ and $14^{\text {th }}$ November 2013 , along these two streams starting from the mine shafts area down to the Tonalli River. The soil from top $10 \mathrm{~cm}$ layer was collected for each sample and the collected soil was then mixed and sieved using a $2 \mathrm{~mm}$ sieve. The soil samples of less than $2 \mathrm{~mm}$ were dried in an oven at $40^{\circ} \mathrm{C}$ for 24 hours prior to chemical analysis and spectral measurements.

\section{CHEMICAL ANALYSIST}

The concentrations of seven elements, namely silver (Ag), arsenic (As), cadmium $(\mathrm{Cd})$, copper $(\mathrm{Cu})$, mercury $(\mathrm{Hg})$, lead $(\mathrm{Pb})$, and zinc $(\mathrm{Zn})$ in the samples were measured. For this purpose, each well-mixed dried soil sample was ground in to a fine powder using a laboratory ball mill. Afterwards, 1 gram from each well-ground sample was used for the chemical analysis while reminder of the sample was kept for spectral measurements. Each soil sample was dissolved in concentrated nitric acid before being placed in a quartz microwave vessel for heating in a microwave unit for approximately 2 hours. After cooling, the vessel contents were allowed to settle. After being diluted to volume, the digested samples were ready for analysis. In this study, inductively coupled plasma mass spectrometry (ICP-MS) was used to determine the metal concentration of the samples. Table 1 shows a summary of the results of heavy metal measurement derived from the chemical analysis for the 53 soil samples.

As Table 1 reveals, high concentrations of arsenic and lead were found. These results confirmed Harrison et al. (2003) findings where they highlighted high concentrations of arsenic and lead in the Yerranderie area.

Table 1. A summary of the heavy metal contents of 53 soil samples from Yerranderie

\begin{tabular}{|c|cccc|}
\hline Heavy metal & Minimum & Maximum & Mean & Std. \\
\hline $\mathrm{Pb}(\% \mathrm{~W} / \mathrm{W})$ & 0.04 & 5.0 & 1.8 & 1.3 \\
$\mathrm{Ag}(\mathrm{mg} / \mathrm{kg})$ & 2.3 & 48.4 & 14.1 & 12.7 \\
$\mathrm{As}(\mathrm{mg} / \mathrm{kg})$ & 311.0 & 20150.0 & 4635.0 & 3876.0 \\
$\mathrm{Cd}(\mathrm{mg} / \mathrm{kg})$ & 4.0 & 64.4 & 18.4 & 13.30 \\
$\mathrm{Cu}(\mathrm{mg} / \mathrm{kg})$ & 59.4 & 2396.5 & 647.9 & 457.0 \\
$\mathrm{Hg}(\mathrm{mg} / \mathrm{kg})$ & 0.03 & 1.7 & 0.4 & 0.3 \\
$\mathrm{Zn}(\mathrm{mg} / \mathrm{kg})$ & 272.0 & 5049.0 & 1509.0 & 908.0 \\
\hline
\end{tabular}

The average metal concentrations derived from the chemical analysis of the samples were compared with the Australian and New Zealand Environment and Conservation Council (ANZECC 2000) guideline as shown in Table 2. The metal content of the soil was found to be greater than the ANZECC standards. Excessive heavy metal pollution was found for lead and arsenic. Also, comparing the metal content of each sample with ANZECC guideline showed that all collected samples exceeded the guidelines for silver, arsenic, cadmium, lead and zinc. Also, $98 \%$ and $87 \%$ of the collected samples contained more than the ANZECC guideline standards for copper and mercury, respectively. 


\section{SPECTRAL MEASUREMENT}

The soil sample spectra were measured using the Analytical Spectral Devices (ASD) FieldSpec 3 spectroradiometer in the laboratory environment. The spectroradiometer was able to collect radiance between $350 \mathrm{~nm}$ to $2500 \mathrm{~nm}$ with $1.4 \mathrm{~nm}(350$ $1000 \mathrm{~nm})$ and $2 \mathrm{~nm}(1000-2500 \mathrm{~nm})$ sampling interval. An average of 30 spectra collected using a Contact Probe was stored as the final spectrum for each soil sample. In order to produce relative reflectance spectra for each sample, radiance spectra were normalized against a 99\% Spectralon white reference.

Table 2. ANZECC limit excesses of heavy metals sampled at Yerranderie

\begin{tabular}{|c|cc|}
\hline Heavy metal & $\begin{array}{c}\text { ANZECC standard } \\
(\mathrm{mg} / \mathrm{kg})\end{array}$ & $\begin{array}{c}\text { ANZECC limit } \\
\text { excess }\end{array}$ \\
\hline $\mathrm{Pb}$ & 50.0 & $\times 358$ \\
$\mathrm{Ag}$ & 1.0 & $\times 14$ \\
$\mathrm{As}$ & 20.0 & $\times 232$ \\
$\mathrm{Cd}$ & 1.5 & $\times 12$ \\
$\mathrm{Cu}$ & 65.0 & $\times 10$ \\
$\mathrm{Hg}$ & 0.15 & $\times 3$ \\
$\mathrm{Zn}$ & 200.0 & $\times 8$ \\
\hline
\end{tabular}

\section{HEAVY METAL MODELLING}

In addition to original reflectance, first and second derivatives were utilised in this study to identify the optimum measurement to model the heavy metal concentrations. Derivatives are usually applied to enhance the spectra appearance (Bogrekci and Lee, 2005). The first derivative of the reflectance measuring the slope of the spectra between the reflectance of two wavelengths (Richardson and Berlyn, 2002) was derived using the following equation (Xavier et al., 2006):

$R^{\prime}\left(\lambda_{i}\right)=\frac{R\left(\lambda_{i+1}\right)-R\left(\lambda_{i-1}\right)}{\lambda_{i+1}-\lambda_{i-1}}$

Where $R^{\prime}\left(\lambda_{i}\right)$ is the first derivative of the reflectance for the wavelength of $\lambda_{i}$. In order to calculate the derivative of the spectra, it is possible to select different gap values determining the size of window which is used to calculate the derivatives. For this study, a gap value of 3 was selected. This means that the reflectance derivative of $\lambda_{i}$ is derived using the calculation of the spectral slope of the reflectance of the next wavelength $\left(\lambda_{i+1}\right)$ and reflectance of the wavelength before $\left(\lambda_{i-1}\right)$. In order to calculate the second derivative of the spectra, the following equation was applied (Xavier et al., 2006):

$R^{\prime \prime}\left(\lambda_{i}\right)=\frac{R^{\prime}\left(\lambda_{i+1}\right)-R^{\prime}\left(\lambda_{i-1}\right)}{\lambda_{i+1}-\lambda_{i-1}}$

Where $R^{\prime \prime}\left(\lambda_{i}\right)$ is the second derivative of the reflectance for the wavelength of $\lambda_{i}$. Stepwise multiple-linear regression as a common modelling method (Shamsoddini et al., 2012; Shamsoddini et al., 2013a) was used to model heavy metal content of the collected soil samples to the reflectance and its derivatives. Multicollinearity and over-fitting are two important issues which should be prevented when multiple-linear regression is utilised. To avoid these problems, tolerance $(T o l)$, condition index $(C I)$ and p-value were calculated. The models for which $T o l$ was lower than $0.1, C I$ higher than 30 and p-value higher than 0.05 were excluded. Gorsuch (1974) and Hair et al. (1995) suggest the minimum ratio of 1:5 for the number of predictors and the number of samples to avoid over-fitting. Consequently, the maximum number of the predictors for the models was set to 5 to ensure prevention of over-fitting.

The model evaluation was implemented using leave-one-out cross-validation (Efron and Tibshirani, 1993) which is commonly used for evaluating the generalisation performance of the models (Shamsoddini, 2012; Shamsoddini et al., 2013b). The coefficient of determination $\left(R^{2}\right)$ and standard error of estimation $(S E E)$ were calculated as the fitness indicators of the models. In addition, the error of estimation derived from $S E E$ calculated for each heavy metal divided by the mean value of the measured heavy metal (shown in Table 1) was reported as a percentage relative error. To compare the accuracy of the models derived from reflectance values and its derivatives, a paired-samples t-test at a significance level of $5 \%$ (pvalue $<0.05$ ) was applied to the absolute residuals between the estimated heavy metal values and field-measured heavy metal values.

\section{RESULTS AND DISSCUSSION}

Figure 2 shows the spectral properties of four samples. While sample 36 (S36) contains the highest amount of zinc, the highest amount of silver was measured for sample 23 (S23). Also, sample 2 (S2) contains highest amounts of copper and cadmium. Finally, highest amounts of mercury, lead, and arsenic pertain to sample 21 (S21). As it is obvious, the general trend of the spectral property of these samples is similar. For example, while these samples show absorption area around $1450 \mathrm{~nm}$, their reflectance increases around $2050 \mathrm{~nm}$. However, they show some differences such as difference in spectral slope around $1800 \mathrm{~nm}$ to $1900 \mathrm{~nm}$; while S36 shows the steepest spectral slope, the spectral slope is not steep for S2 and S21 for theses wavelengths.

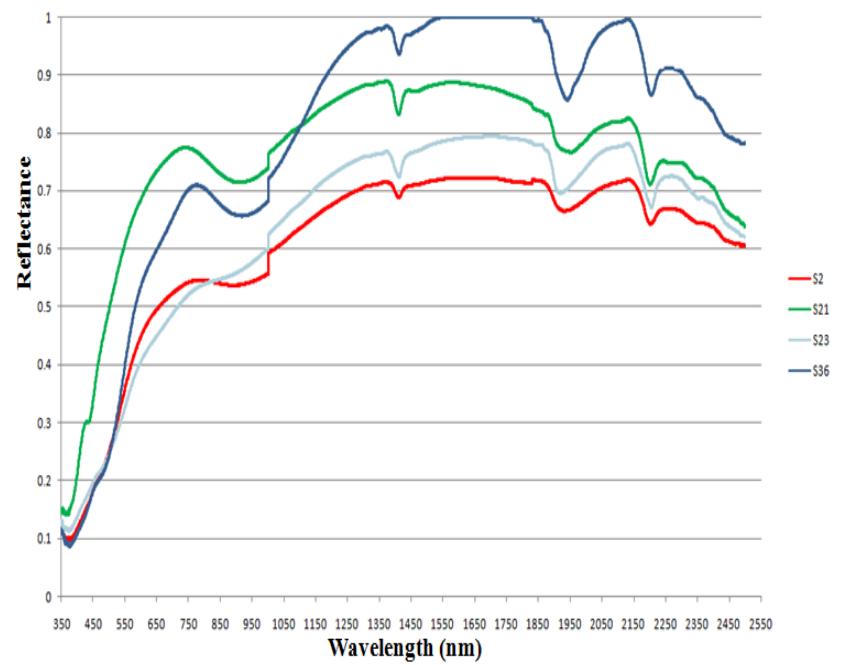

Figure 2. spectral properties of the soil samples measured by spectroradiometer

After selecting the best performing models corresponding to higher $R^{2}$ and lower $S E E$, the selected models were validated and the result is shown in Table 3. The best results derived for estimating each heavy metal is indicated by bold text in the Table. While the models derived from original reflectance resulted in poor correlation with estimated heavy metal 
concentrations, applying first and second derivative reflectance data significantly improved the performance of the models, as the t-test results, shown in Table 4, indicate.

Table 3. The estimation results of heavy metals after validation

\begin{tabular}{|c|cccc|}
\hline $\begin{array}{c}\text { Heavy } \\
\text { metal }\end{array}$ & Data & $\mathrm{R}^{2}$ & $\mathrm{SEE}$ & $\begin{array}{c}\text { Relative } \\
\text { error }(\%)\end{array}$ \\
\hline $\mathrm{Pb}(\%)$ & Reflectance & 0.16 & 1.24 & 69.0 \\
& $1^{\text {st }}$ derivative & $\mathbf{0 . 8 3}$ & $\mathbf{0 . 5 8}$ & $\mathbf{3 2 . 3}$ \\
& $2^{\text {nd }}$ derivative & 0.76 & 0.68 & 38.1 \\
$\mathrm{Ag}$ & Reflectance & 0.05 & 12.6 & 88.9 \\
$(\mathrm{mg} / \mathrm{L})$ & $1^{\text {st }}$ derivative & 0.47 & 9.80 & 69.4 \\
& $2^{\text {nd }}$ derivative & $\mathbf{0 . 5 7}$ & $\mathbf{8 . 7 3}$ & $\mathbf{6 1 . 8}$ \\
& & & & \\
$\mathrm{As}$ & Reflectance & 0.73 & 2074 & 44.7 \\
$(\mathrm{mg} / \mathrm{L})$ & $1^{\text {st }}$ derivative & $\mathbf{0 . 9 0}$ & $\mathbf{1 2 6 7}$ & $\mathbf{2 7 . 3}$ \\
& $2^{\text {nd }}$ derivative & 0.74 & 2066 & 44.6 \\
& & & & \\
$\mathrm{Cd}$ & Reflectance & 0.16 & 12.4 & 67.3 \\
$(\mathrm{mg} / \mathrm{L})$ & $1^{\text {st }}$ derivative & 0.59 & 9.05 & 49.2 \\
& $2^{\text {nd }}$ derivative & $\mathbf{0 . 6 6}$ & $\mathbf{8 . 1 7}$ & $\mathbf{4 4 . 4}$ \\
& & & & \\
$\mathrm{Cu}$ & Reflectance & 0.10 & 438.8 & 67.7 \\
$(\mathrm{mg} / \mathrm{L})$ & $1^{\text {st }}$ derivative & $\mathbf{0 . 7 3}$ & $\mathbf{2 4 8 . 5}$ & $\mathbf{3 8 . 4}$ \\
& $2^{\text {nd }}$ derivative & 0.73 & 249.9 & 38.6 \\
& & & & \\
$\mathrm{Hg}$ & Reflectance & 0.13 & 0.32 & 78.9 \\
$(\mathrm{mg} / \mathrm{L})$ & $1^{\text {st }}$ derivative & 0.69 & 0.19 & 47.8 \\
& $2^{\text {nd }}$ derivative & $\mathbf{0 . 7 3}$ & $\mathbf{0 . 1 8}$ & $\mathbf{4 4 . 2}$ \\
& & & & \\
$\mathrm{Zn}$ & Reflectance & 0.24 & 809.7 & 53.7 \\
$(\mathrm{mg} / \mathrm{L})$ & $1^{\text {st }}$ derivative & $\mathbf{0 . 7 4}$ & $\mathbf{4 8 8 . 6}$ & $\mathbf{3 2 . 4}$ \\
& $2^{\text {nd }}$ derivative & 0.64 & 574.3 & 38.1 \\
\hline
\end{tabular}

The original reflectance of the soil samples carries some noise (Stevens et al., 2005) due to the difference in the grain size and surface roughness (You et al., 2014). Although, a grinding process was used to make the soil particle as small as possible, there were some samples for which the soil particles remained larger than the other samples. This variance in size could have contributed towards poor performance of the models derived from original reflectance data. Perhaps, for these reasons, use of a noise reduction filter, e.g. mean filter, appears to be useful to smooth the signal and reduce the level of noise on this data (Butkutë, 2005). As Table 3 shows, while the models derived from the second derivative of the reflectance performed better to estimate silver, cadmium, and mercury, Table 4 indicates that there is no significant difference between these models and those derived from the first derivatives of the reflectance for estimating these heavy metals. According to Table 3, the models derived from the first derivative have estimated lead, arsenic, copper, and zinc better than the models derived from the other datasets; however, arsenic is the only heavy metal which is estimated significantly more accurate through the first derivative reflectance data compared to that derived from the second derivate reflectance data (see Table 4).

The performance of the models estimating the heavy metal content of the soil highly depends on the method which is used for pre-processing of the reflectance spectra (Kemper and Sommer, 2002; Ren et al., 2009). Overall results of this study demonstrate the necessity to apply derivatives, especially first derivative method, on the original spectra prior to modelling of the heavy metals. The effects of spectral interference and baseline, which were probably caused by the differences in the grain size rather than in heavy metal content, can be reduced by applying derivative transformations, including first and second derivative, on the original reflectance (Kemper and Sommer, 2002; Wu et al., 2005). Also, use of derivatives can result in the enhancement of the minor absorption features and consequently more spectral features explaining the variability of the heavy metal content (Ren et al., 2009). Although, the second derivative more efficiently removes baseline effects and enhances the absorption features, it can be more sensitive to noise compared to the first derivative (Kemper and Sommer, 2002). The sensitivity of the second derivative towards noise was evidenced in this study and the models derived from the first derivative of the reflectance have performed better than those derived from the second derivative of the reflectance.

Table 4. Paired-samples t-test results for comparison of the models derived from different data

\begin{tabular}{|c|c|c|c|c|}
\hline $\begin{array}{l}\text { Heavy } \\
\text { metal }\end{array}$ & Data & Reflectance & $\begin{array}{c}1^{\text {st }} \\
\text { derivative } \\
\end{array}$ & $\begin{array}{c}2^{\text {nd }} \\
\text { derivative }\end{array}$ \\
\hline \multirow{3}{*}{$\mathrm{Pb}$} & Reflectance & --------- & 0.000 & 0.000 \\
\hline & $1^{\text {st }}$ derivative & 0.000 & --------- & 0.124 \\
\hline & $2^{\text {nd }}$ derivative & 0.000 & 0.124 & --------- \\
\hline \multirow{3}{*}{$\mathrm{Ag}$} & Reflectance & & 0.013 & 0.001 \\
\hline & $1^{\text {st }}$ derivative & 0.013 & --------- & 0.130 \\
\hline & $2^{\text {nd }}$ derivative & 0.001 & 0.130 & --------- \\
\hline \multirow{3}{*}{ As } & Reflectance & & 0.006 & 0.804 \\
\hline & $1^{\text {st }}$ derivative & 0.006 & ---------- & 0.000 \\
\hline & $2^{\text {nd }}$ derivative & 0.804 & 0.000 & ---------- \\
\hline \multirow{3}{*}{$\mathrm{Cd}$} & Reflectance & & 0.011 & 0.011 \\
\hline & $1^{\text {st }}$ derivative & 0.011 & ----- & 0.702 \\
\hline & $2^{\text {nd }}$ derivative & 0.011 & 0.702 & \\
\hline \multirow{3}{*}{$\mathrm{Cu}$} & Reflectance & & 0.000 & 0.000 \\
\hline & $1^{\text {st }}$ derivative & 0.000 & ---------- & 0.560 \\
\hline & $2^{\text {nd }}$ derivative & 0.000 & 0.560 & \\
\hline \multirow{3}{*}{$\mathrm{Hg}$} & Reflectance & ---------- & 0.001 & 0.002 \\
\hline & $1^{\text {st }}$ derivative & 0.001 & -------- & 0.652 \\
\hline & $2^{\text {nd }}$ derivative & 0.002 & 0.652 & ---------- \\
\hline \multirow{3}{*}{$\mathrm{Zn}$} & Reflectance & ------- & 0.001 & 0.019 \\
\hline & $1^{\text {st }}$ derivative & 0.001 & --------- & 0.361 \\
\hline & $2^{\text {nd }}$ derivative & 0.019 & 0.361 & ----------- \\
\hline
\end{tabular}

As Table 3 shows, among different heavy metals, more than $80 \%$ of the variability of arsenic and lead is explained by the first derivative of the reflectance. Also, more than $70 \%$ variability of the variability of copper and zinc is explained by these data. Moreover, arsenic, lead, and zinc are estimated more accurately than other heavy metals while estimation of $\mathrm{Ag}$ concentration attracted the highest (more than $60 \%$ ) error.

\section{CONCLUSION}

The estimation of soil heavy metal contamination using spectroscopic method was investigated in this study of samples from along stream adjacent to shafts of the derelict former Yerranderie silver-lead-zinc mines in the Blue Mountains National Park, NSW, Australia. The results of the chemical analysis showed that the derelict Yerranderrie mine area impacts the soil of downstream areas. The soil is mainly contaminated by lead and arsenic. The results of this study show that these two heavy metals were estimated more accurately than the other heavy metals using spectroscopic data. Also, it 
was shown that copper and zinc can be estimated with $R^{2}$ of more than 0.70 while the silver content of the soil was estimated less accurately than the other heavy metals. Finally it was shown that while the first derivative of the reflectance data is the most suitable option for modelling the heavy metals, the models derived from the original reflectance data performed poorly. Although, the models derived from applying stepwise multiple-linear regression on the first derivative of reflectance data were promising for estimating most of the heavy metals in this study, further investigation is required to evaluate the effects of other factors such as feature selection method and modelling method on the accuracy of the estimates. From a environmental management and water quality perspective, the results indicate that mitigation measures for heavy metal contamination should be implemented together with regular monitoring of areas surrounding the Yerranderie derelict mine site, especially those areas from which water runoff and streams flow to feed reservoirs that are a sources of drinking water.

\section{Acknowledgement}

Authors would like to acknowledge the funding support from the Faculty of Engineering, UNSW to carry out this project. National Parks and Wildlife Service, Office of Environment and Heritage NSW are also acknowledged for their approval to conduct this research in the Yerranderie area. Also the background information and encouragement provided by Associate Professor John Merson, Executive Director, Blue Mountains World Heritage Institute, is much appreciated.

\section{Reference}

Archer, M. \& Caldwell, R., 2004. Response of six Australian plant species to heavy metal contamination at an abandoned mine site. Water, air, and soil pollution, 157, pp. 257-267.

Bogrekci, I. \& Lee, W., 2005. Spectral measurement of common soil phosphates. Transactions - American Society of Agricultural Engineers, 48, pp. 2371-2378.

Butkutë, B.,2005. Effect of the calibration model on the correlation between spectral data and nitrogen content in various agricultural objects," Chemija, 16, pp. 45-52.

Harrison, J., Heijnis, H., \& Caprarelli, G., 2003. Historical pollution variability from abandoned mine sites, greater blue mountains world heritage area, New South Wales, Australia. Environmental Geology, 43, pp. 680-687.

Järup, L., 2003. Hazards of heavy metal contamination. British Medical Bulletin, 68, pp. 167-182.

Kemper, T. and Sommer, S., 2002. Estimate of heavy metal contamination in soils after a mining accident using reflectance spectroscopy. Environmental Science \& Technology, 36, pp. 2742-2747.

Malley, D. \& Williams, P., 1997. Use of near-infrared reflectance spectroscopy in prediction of heavy metals in freshwater sediment by their association with organic matter. Environmental Science \& Technology, 31, pp. 3461-3467.

Nicolaï, B.M., Beullens, K., Bobelyn, E., Peirs, A., Saeys, W., Theron, K.I., \& Lammertyn, J., 2007. Nondestructive measurement of fruit and vegetable quality by means of NIR spectroscopy: A review. Postharvest Biology and Technology,46, pp. 99-118.
Ren, H.-Y., Zhuang, D.-F., Singh, A.N., Pan, J.-J., Qiu, D.-S., \& Shi, R.-H., 2009. Estimation of As and Cu contamination in agricultural soils around a mining area by reflectance spectroscopy: A case study. Pedosphere, 19, pp. 719-726.

Richardson, A.D. \& Berlyn, G.P., 2002. Changes in foliar spectral reflectance and chlorophyll fluorescence of four temperate species following branch cutting. Tree Physiology, 22, pp. 499-506.

Schwartz, G., Eshel, G. and Ben-Dor, E., 2011. Reflectance spectroscopy as a tool for monitoring contaminated soils. In Soil Contamination Edited by: Pascucci, S. 67-90. InTech: Manhattan, NY.

Shamsoddini, A., 2012. Radar backscatter and optical textural indices fusion for pine plantation structure mapping. In: ISPRS Annals of the Photogrammetry, Remote Sensing and Spatial Information Sciences, Melbourne, I-7, pp. 309-314.

Shamsoddini, A., Trinder, J. C., \& Turner, R., 2012. SPOT-5 multispectral image for pine plantation structure mapping. In: ACRSC2012 Proceedings, Thailand, pp. 1-10.

Shamsoddini, A., Trinder, J. C., \& Turner, R., 2013a. Pine plantation structure mapping using WorldView-2 multispectral image. International Journal of Remote Sensing, 34, pp. 39864007.

Shamsoddini, A., Turner, R. \& Trinder, J. C., 2013b. Improving lidar-based forest structure mapping with crown-level pit removal. Journal of Spatial Science, 58, pp. 29-51.

Stevens, A., van Wesemael, B., Vandenschrick, G., Touré, S., \& Tychon, B., 2006. Detection of carbon stock change in agricultural soils using spectroscopic techniques. Soil Science Society of America Journal, 70, pp. 844-850.

Wright, I.A., 2006. Australian freshwater midges (Chironomidae: Diptera). Ph.D. thesis, University of Western Sydney, Australia.

Wu, Y.Z., Chen, J., Ji, J.F., Tian, Q.J., \& Wu, X.M., 2005. Feasibility of reflectance spectroscopy for the assessment of soil mercury contamination. Environmental Science \& Technology, 39, pp. 873-878.

You, J., Xing, L., Liang, L., Pan, J., \& Meng, T., 2014. Application of short-wave infrared (SWIR) spectroscopy in quantitative estimation of clay mineral contents. In: IOP Conference Series: Earth and Environmental Science. 2014. IOP Publishing, 17, pp. 1-6.

Xavier, A.C., Rudorff, B.F.T., Moreira, M.A., Alvarenga, B.S., Freitas, J.G.d. \& Salomon, M.V., 2006. Hyperspectral field reflectance measurements to estimate wheat grain yield and plant height. Scientia Agricola, 63, pp. 130-138. 